

Original Research Article

\title{
Drug utilization among diabetes mellitus patients in a tertiary care hospital in North-East India
}

\author{
Khuarijam Linda Devi ${ }^{1, *}$, Indira Raleng ${ }^{1}$, Zosangliani Sailo ${ }^{1}$, Varkung Valte ${ }^{1}$ \\ ${ }^{1}$ Dept. of Pharmacology, Jawaharlal Nehru Institute of Medical Sciences, Imphal, Manipur, India
}

\section{A R T I C L E I N F O}

\section{Article history:}

Received 18-07-2020

Accepted 18-08-2020

Available online 23-10-2020

\section{Keywords:}

Cross-sectional study

Diabetes mellitus

Drug utilization

Hyperglycemia

Health planning

Medical compliance questionnaire

\begin{abstract}
A B S T R A C T
Introduction: Diabetes mellitus (DM) is a spectrum of common metabolic disorders, arising from a variety of pathogenic mechanisms, all resulting in hyperglycemias. Drug utilization study of anti-diabetic agent is of paramount importance to promote rational drug use and also to make available valuable information for health planning.

Aims: The present study was taken up to explore into the drug-utilization pattern among diabetic patients. Materials and Methods: A cross-sectional study was carried out in the Department of Pharmacology in collaboration with Medicine Department, JNIMS, Porompat during May 2018 - April 2020. A total of 100 patients aged 18 years or more with the clinical diagnosis of type II DM and admitted in the Medicine Ward were the study-subjects. Patients with co-morbid conditions were excluded from the study. Information on the medical compliance profile was collected by using the Medical Compliance Questionnaire.

Results: Females outnumbered males in the ratio of 1.2:1. The mean age of the patients is 55.03 years with a standard deviation (SD) of 8.58 years. The proportion of patients who took the prescribed drugs without any interruption was $66 \% .64 \%$ of the patients never thought of giving up the medications in any circumstance, even though they started feeling better. $63 \%$ of the patients always carried the medications with them when they are away from home.

Conclusion: The treatment adherence to medications among the study-subjects was found to be $66 \%$. This variation might be because of inadequate counseling during starting of the therapy and also during the follow-up periods. This issue needs to be focused while initiating diabetic medications.
\end{abstract}

(C) 2020 Published by Innovative Publication. This is an open access article under the CC BY-NC license (https://creativecommons.org/licenses/by-nc/4.0/)

\section{Introduction}

Diabetes mellitus (DM) is a spectrum of common metabolic disorders, arising from a variety of pathogenic mechanisms, all resulting in hyperglycaemias. It is a serious public health problem because of its high incidence in the population, its complications, mortality, high financial and social cost involve in the treatment and a significant deterioration in the quality of life of the people. ${ }^{1}$

The worldwide prevalence of Diabetes mellitus (DM) has risen dramatically over the past two decades from an estimated 30 million cases in 1985 to 425 millions in 2019. Based on current trends, the International Diabetes Federation projects that 592 million individuals will have

\footnotetext{
* Corresponding author.

E-mail address: lindadevikh@gmail.com (K. L. Devi).
}

diabetes by the year $2035 .^{2}$

India leads the world with largest number of diabetes subject earning the dubious distinction of being termed as the diabetes capital of the world. ${ }^{3}$ The prevalence of diabetes in Indian adults was found to be $2.4 \%$ in rural and $4.0 \%-11.6 \%$ in urban dwellers. ${ }^{4}$ India is presently estimated to have 41 million individuals affected by this deadly disease with every fifth diabetic in the world being an Indian. 5

Being a chronic disease with no known curative therapy, the only option for the optimal glucose control is through the strict adherence to medication, diet and life style modifications. And many a times, patients do not adhere to the therapy because of many reasons. The World Health Organization defines "drug utilization" as the 
marketing distribution, prescription and use of the drugs in a society considering its medical, social, and economic consequences. ${ }^{6-8}$

Drug utilization study of anti-diabetic agent is of paramount importance to promote rational drug use and also to make available valuable information for health planning. Yet, research publications regarding this issue in the northeastern part of India are very few in number. Hence, it was felt important to take up the present study.

\section{Aims}

The present study was taken up to explore into the drugutilization pattern among diabetic patients

\section{Materials and Methods}

After obtaining the approval from the Institutional Ethical Committee, JNIMS, and written informed consent from the patient a cross-sectional study was carried out in the Department of Pharmacology in collaboration with Medicine Department, JNIMS, Porompat. which is the only state-owned teaching medical institution. The study period was for two years starting from May 2018. Patients aged of 18 years or more with the clinical diagnosis of type II DM and admitted in the Medicine Ward were the studysubjects. Patients with co-morbid conditions (heart diseases, hypercholesterolemia, chronic lung diseases, and diseases of the nervous system like Parkinson's disease or Multiple Sclerosis and hypertension were excluded from the study. Also those patients who refused to participate in the study were excluded.

A sample size of 213 was scientifically calculated by taking into consideration an existing prevalence rate of $16.63 \%,{ }^{9}$ a confidence level of $95 \%$ and an absolute error of 5 . Consecutive eligible study-subjects were enrolled by using purposive sampling technique.

Case records of the patients which were focused on the socio-demographic profile of the patients and a pre-tested interview schedule which had sections on the clinical history including present and past history as well as family history. Lastly, information on the medical compliance profile was collected by using the Medical Compliance Questionnaire (MCQ) ${ }^{10}$ which was modified to suit the local situation.

Collected data were entered in MS excel sheet which was later transported to SPSS.v23. Only descriptive statistics (Mean, SD, proportions) were used for data analysis and presentation.

\section{Results}

At the time of writing this interim report, datas were collected from a total of 100 patients. Females outnumbered males in the ration of 1.22:1. (Figure 1) Their ages ranged from 26 to 70 years, the mean age (standard deviation) being 55.03 (8.58) years.

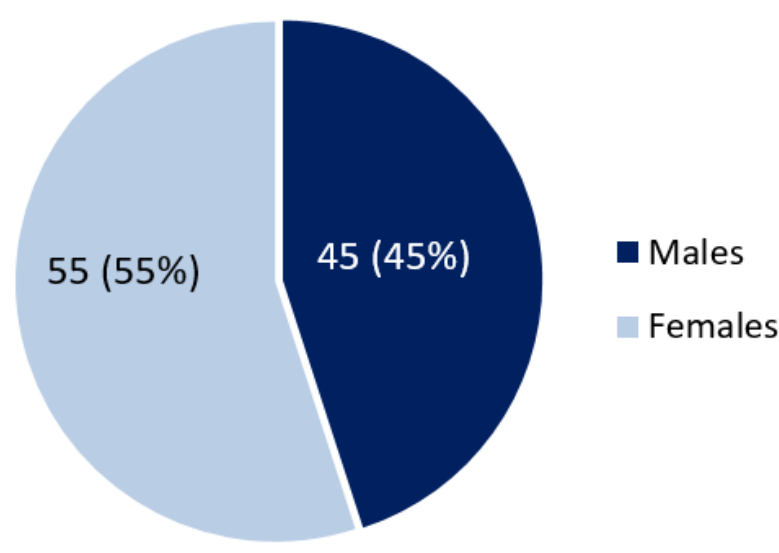

Fig. 1: Distribution of study subjects by gender

A total of 40 patients $(40 \%)$ had insulin injection as the primary form of medical therapy out of which 07 used to take oral hypoglycemic drugs or absorbent inhibitors. Metformin in the dosage of 500 or $1000 \mathrm{mg}$ was used by 57 patients $(57 \%)$ along with other drugs. Fifty-one $(51 \%)$ patients were under treatment with a single medication; 22 $(22 \%)$ were on double medication and the remaining 27 patients $(27 \%)$ were on more than two drugs. (Figure 2)

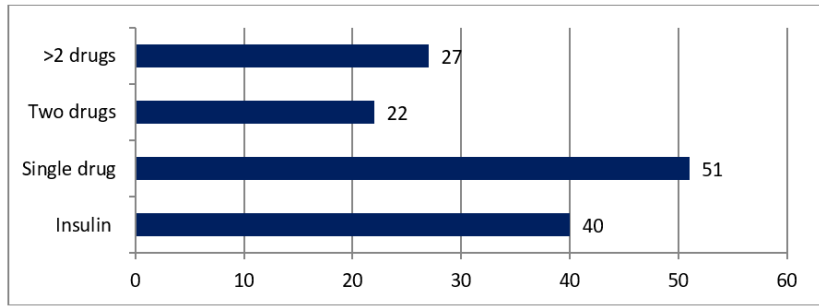

Fig. 2: No. and type of drugs used in treatment of Diabetes mellitus

Voglibose was the drug used as absorbent inhibiter and was prescribed to one-tenth of all the patients (10\%). Seven patients $(7 \%)$ were taking a combination of metformin and glimiperide. One patient was taking teneligliptin in addition to metformin and glimiperide and another patient was on metformin, glimiperide and gl.

Two-thirds $(66 ; 66 \%)$ of the patients used to take the prescribed drugs without any interruption; but one-third (33: $33 \%$ ) used to forget taking the drug(s) sometimes while one patient used to take it very irregularly.

A majority of the patients $(64 ; 64 \%)$ never thought of giving up the medications. But the remaining $36 \%$ decided to stop taking the drugs at some point of time (29 sometimes, 05 often and 02 almost always). Even though they started feeling more than half of them $(59 ; 59 \%)$ never missed taking the medications whereas 34 of them $(35 \%)$ sometimes missed it and 06 of them $(6 \%)$ gave up the medications. Almost one-third of them $(31 ; 31 \%)$ tried reducing the dose by themselves when they started feeling 
Table 1: Treatment adherence among study-subjects $(n=100)$

\begin{tabular}{lcccc}
\hline Particulars & Never & Sometimes & Often & 1 \\
Forgetting to take medicine & 66 & 33 & 5 & Always \\
Deciding not to take medicine & 64 & 29 & 1 & 2 \\
Missing medicine when felt better & 59 & 34 & 3 & 6 \\
Deciding to take less medicine & 92 & 5 & 2 & 0 \\
Stopping medication due to sick effect & 86 & 11 & - & - \\
Forgetting to take drug during travel & 63 & 37 & - & - \\
Not taking medicine as stock out at home & 62 & 38 & \\
\hline
\end{tabular}

better during the course of the treatment.

Majority of the patients $(87 ; 87 \%)$ never stopped taking the medications although they felt sick of the medications. But $11(11 \%)$ sometimes stopped it and another 03 patients $(03 \%)$ used to stop it often/always. During travel away from home, more than one-third of them $(37 ; 37 \%)$ used to forget taking the drugs along with them whereas the remaining 63 (63\%) always carried them with them.

Lastly, nearly two-fifths of them $(38 ; 38 \%)$ had to stop taking the drugs sometimes when the home-stock was nil whereas, the remaining $62 \%$ somehow managed to continue the drugs without any interruption. (Table 1 and Figure 3)

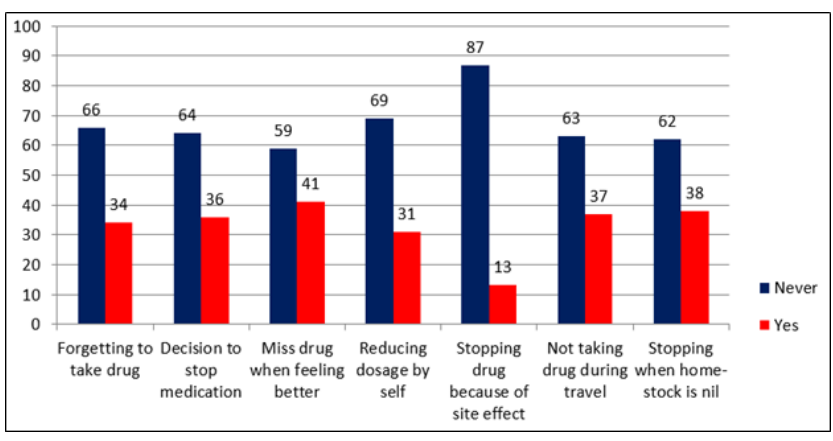

Fig. 3: Treatment adherence pattern

${ }^{*} \mathrm{x}$ axis represents adherence pattern and $\mathrm{y}$ axis represents number of patients)

\section{Discussion}

Treatment regimens and type of drugs used vary across the world. Ashutosh $\mathrm{K}$ et al. concluded that $30 \%$ of the treatments was based on monotherapy and metformin was the commonetly used drug whereas Suthar SD et al. found that $29.6 \%$ of the treatment regimens was based on monotherapy with insulin being the most commonly used drug. ${ }^{8,9}$ In the present study, $51 \%$ of the patients were on monotherapy. Metformin was the most commonly used drug $(57 \%)$ and insulin was the next frequently used drug (40\%). The variations might be because of the type of patient and the study place. Also, the experience of the treating physician might have a role in it.
A wide range of treatment adherence among diabetic patients was observed by different researches from various parts of the world. Jemal A et al in Ethiopia found a treatment rate of $70.4 \%$ among type II DM. ${ }^{10}$ In India Anumol $\mathrm{M}$ et al. found it to be as low as $57 \%$ only. ${ }^{11}$ From the present study, the treatment adherence was found to be in between these two earlier findings (66.6\%). Again, the year of study, region where the studies were done, the type of patients and the background characteristics of the patients might have an influence on the drug adherence.

The present study is one of its first kind in the northeastern part of the country and might help in health policy planning regarding diabetes program in the region. Nevertheless, the study had certain limitations as it is only an interim report pertaining to 100 patients only. Hence, the findings may not be generalizable.

\section{Conclusion}

The treatment adherence to medications among the studysubjects was found to be $66 \%$. But more important than the quantitative figures in treatment adherence pattern is that one-third of the patients $(36 \%)$ deciding to stop medication at some point of time, almost half $(41 \%)$ of them thinking of stopping the drug when they started feeling better, one-third $(31 \%)$ trying to reduce the number of medicines, another one-third $(37 \%)$ forgetting to take the medicine with them when they travel away from home and more than one-third (38\%) stopping the medications when the home-stock ran out. This might be because of inadequate counseling during starting of the therapy and also during the follow-up periods. Endocrinologists along with thier counsellors need to keep this issue in their mind while initiating diabetic medications.

Bigger studies are warranted to bring a valid conclusion which will be generalizable. If factors are amiable, community-based studies may give more accurate results.

\section{Source of Funding}

None.

\section{Conflict of Interest}

None. 


\section{References}

1. Powers AC, D'alessio D. Endocrine Pancreas and Pharmacotherapy of Diabetes Mellitus and Hypoglycemia. In: Goodman \& Gilman's: The Pharmacological basis of Therapeutics. New York: McGraw Hills; 2011. p. 1237-73.

2. White JR. Improving adherence in the treatment of Type 2 diabetes. Diabetes. 2010;36(4):11-5.

3. Nunes MI. The relationship between quality of life and adherence to treatment. Curr Hypertens Rep. 2001;3(6):462-5.

4. Pietrzykowska E, Zozulinska D, Wierusz-Wysocka B. Quality of life of patients with diabetes. Pol Merkur Lekarski. 2007;23(136):311-4.

5. Alvin C, Kasper DL. Diabetes Mellitus. In: Harrison's Principles of Internal Medicine. New York: McGraw Hills; 2015. p. 2413-35.

6. Shah A, Afzal M. Prevalence of diabetes and hypertension and association with various risk factors among different Muslim populations of Manipur, India. $J$ Diabetes Metab Disord. 2013;12(1):52.

7. Aguilar CAP, Martínez YV, Bernal YS, Martínez RR, Ulloa RA Performance of two questionnaires to measure treatment adherence in patients with Type-2 Diabetes. BMC Public Health. 2009;9:38.

8. Ashutosh K, Ipseeta RM, Sandeep R. Assessment of Prescription Pattern of Antidiabetic Drugs in the Outpatient Department of a Tertiary Care Hospital. Int J Clin Endocrinol Metab. 2017;3(1):1-7.

9. Suthar SD, Dholaria NK, Chavda DA, Chacko J, Bhansali NB, Gosai TR, et al. Drug utilization study in diabetic patients attending medicine outpatient department of a tertiary care hospital. Int J Diabetes Dev Ctries. 2015;35(1):8-13
10. Jemal A, Abdela J. Adherence to Oral Antidiabetic Medications among Type 2 Diabetic (T2DM) Patients in Chronic Ambulatory Wards of Hiwot Fana Specialized University Hospital, Harar, Eastern Ethiopia: A Cross Sectional Study. J Diabetes Metab. 2017;08(01):721.

11. Anumol M, Anusree TK, Aparna MA, Archana S, Athira M, Sachina BT. Quality of life among type II diabetes mellitus in south India, a descriptive study. Am Int J Res Humanit, Arts Soc Sci. 2014;7(2):197200.

\section{Author biography}

Khuarijam Linda Devi Post Graduate Trainee

Indira Raleng Tutor

Zosangliani Sailo Post Graduate Trainee

Varkung Valte Professor and HOD

Cite this article: Devi KL, Raleng I, Sailo Z, Valte V. Drug utilization among diabetes mellitus patients in a tertiary care hospital in North-East India. Indian J Pharm Pharmacol 2020;7(3):177-180. 